\title{
EXPERIMENTAL INVESTIGATION IN PREDICTING FRICTION STIR WELD PROCESS PARAMETERS FOR DISSIMILAR AA7075T651 - AA6061T651 BUTT JOINTS
}

\author{
${ }^{1}$ Ravikumar S., ${ }^{2}$ Seshagiri Rao V., ${ }^{3}$ Ramachandran S., ${ }^{4}$ Nagalingeswara Raju B. \\ ${ }^{1}$ Research Scholar, Dept of Mechanical and Production Engineering, Sathyabama University, Chennai. \\ ${ }^{2}$ Dept of Mechanical Engineering, St. Joseph College of Engineering, Chennai. \\ ${ }^{3}$ Dept of Mechanical Engineering, Sathyabama University, Chennai. \\ ${ }^{4}$ Principal, RVS College of Engineering and Technology, Karaikal.
}

\section{Abstract}

Aluminium alloys have gathered wide acceptance in the fabrication of light weight structures requiring a high strength-to weight ratio and good corrosion resistance. Modern structural concepts demand reductions in both the weight as well as the cost of the production and fabrication of materials. Therefore welding processes have proven more attractive, and there is an urgency to study their potential. Compared to the fusion welding processes that are routinely used for joining structural aluminium alloys, friction stir welding (FSW) process is an emerging solid state joining process was invented in 1991 by TWI, in which the material that is being welded does not melt and recast. The major advantage in FSW process is that the maximum temperature reached is less than $80 \%$ of the melting temperature (TM), i.e. the joint is performed in the solid-state and excessive micro structural degradation of the weld zone is avoided. This process uses a non-consumable tool to generate frictional heat in the abutting surfaces. The welding parameters such as tool rotational speed, welding speed, axial force etc., and tool pin profile play a major role in deciding the joint strength. This paper focus on Tensile, Impact and Bending strength with hardness evaluation for predicting the process parameters in varying rotational and welding speeds of friction-stir welding for the dissimilar precipitation hardenable aluminium alloys ie., between 6xxx (Al-Mg-Si) and 7xxx (Al-Zn-Mg).

Keywords: Friction stir welding, Dissimilar Aluminium alloys, Tensile strength, Impact strength, Bending strength, hardness, Pin profiles

\section{INTRODUCTION}

\section{A. Introduction}

In this work, two grade of age hardenable aluminium alloys, namely AA6061 and AA7075 have been chosen for experimental work. AA6061-T651 alloys are high strength aluminium (Al), magnesium $(\mathrm{Mg})$ and silicon $(\mathrm{Si})$ alloys that contains manganese to increase their ductility and toughness. Alloys are readily welded, but they suffer from severe softening in the heat affected zones (HAZ) because of dissolution of $\mathrm{Mg}_{2} \mathrm{Si}$ precipitates during the thermal cycle. It is therefore appropriate to overcome or minimize the HAZ softening with respect to the fusion welding, in order to improve the mechanical properties. AA7075-T651 is a precipitation hardened aluminium alloy widely used in aerospace application owing to its high strength. In the conventional tungsten inert gas (TIG) and laser welding processes, dendrite structure develops in the fusion zone that leads to a drastic decrease in strength which is one of the major mechanical properties. The friction stir welding (FSW) process is a solid state welding process, therefore the solidification microstructure is absent in the welded metals and the presence of brittle inter-dendrite and eutectic phases is avoided. Traditionally, Joints between dissimilar materials these combinations in aerospace structures have been mostly made by riveting. This metal causes stress concentrations and increases the weight of the final joints, there by limiting the application of this process in the aerospace industry ( $\mathrm{P}$ Bahemmat et al). FSW can be used in order to improve weld ability without great loss of strength and corrosion properties.

\section{B. Friction stir welding (FSW)}

The earliest reference to the use of frictional heat for solid phase welding and forming appeared over a century ago in a US patent. A period of fifty years then passed before any significant advancement in friction technology took place, namely a British patent in 1941 that introduced what is known a friction surfacing. Yet another fifty years went by before friction stir welding (FSW) was invented at The Welding Institute (TWI), UK. This comparatively recent innovation has permitted friction technology to be used to produce continuous 
welded seams for plate fabrication, particularly in light alloys. Compared to many of the fusion welding processes that are routinely used for joining structural alloys, friction stir welding (FSW) is an emerging solid state joining process in which the material that is being welded does not melt and recast. Friction stir welding is a continuous, hot shear, autogenous process involving non-consumable rotating tool of harder material than the substrate material. Fig 1 represents the working principle of FSW process. When alloys are friction stir welded, phase transformations that occur during the cool down of the weld the weld are of a solid-state type. Due to the absence of parent metal melting, the new FSW Process observed to offer several advantages over fusion welding. The benefits that stand out most are welding of difficult to weld aluminium alloys such as $2 x x x$ and $7 x x x$ series, better retention of base line material properties, fewer weld defects, low residual stresses, and the better dimensional stability of welding structure. Also FSW is an environmentally cleaner process, due to the absence of a need for the various gases that normally accompanied fusion welding. No consumable filler material or profiled edge preparation is normally necessary An FSW joint usually consists of four different regions as shown in Fig. They are (a) Unaffected base metal (b) Heat affected zone (HAZ) (c) Thermomechanically affected zone (TMAZ) and (d) stir (SZ) zone. The formation of above regions is affected by the material flow behavior under the action of rotation non-consumable tool however; the material flow behavior is predominantly influenced by the FSW tool profiles and FSW process parameters. Fig 2 represents the transverse section various zones of FSW process.

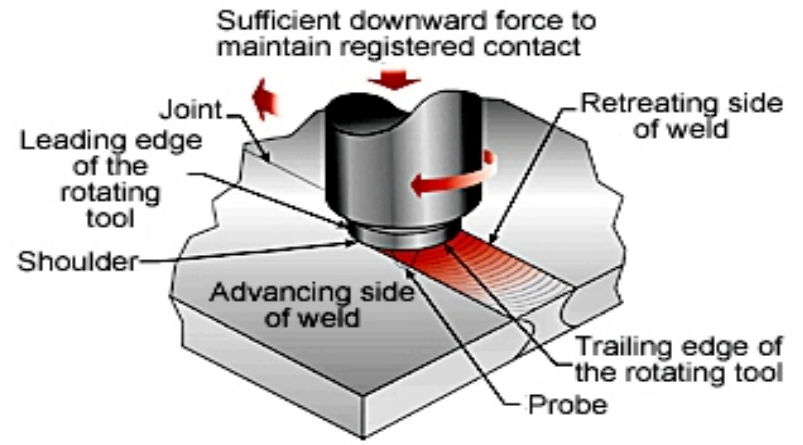

Fig. 1 Schematic of friction stir welding process

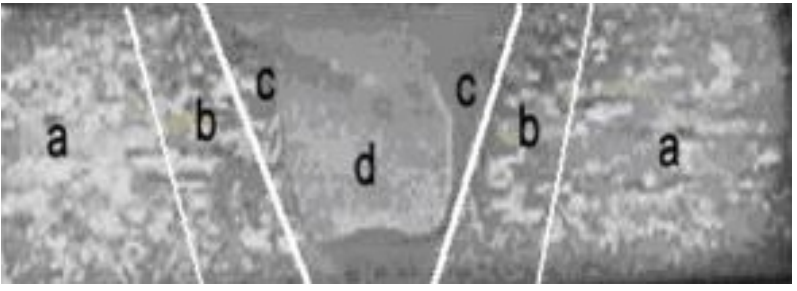

Fig. 2 Different regions of FSW joint: (a) unaffected base metal; (b) heat affected zone (HAZ);

(c) thermo-mechanically affected zone (TMAZ);

(d) Stir (SZ) zone.

There are two different modes of material flow regimes involved in the friction stir weld formation; namely "pin-driven flow" and "shoulder-driven flow". These material flow regimes merge together to form a defect-free weld. A very good overview of friction stir welding has been given by Terry Khalid. [1]. In an attempt to avoid confusion and duplication, TWI proposed an initial basic terminology at an early stage of the development of friction stir welding (FSW). This terminology has since been revised and extended in consultation with licensees and other interested parties are summarized. A definitive standard on FSW is being prepared by Working Group B1 of Commission III of the International Institute of Welding is expected to adopted as an ISO standard. This terminology is given by P.L. Threadgill [2]. The FSW process is a solid-state welding process in which an inconsumable rotating pin is inserted into the adjoining edges of the sheets to be welded with a proper tilt angle and then moved all along the joint. The pin produces frictional and plastic deformation heating in the welding zone. Furthermore, as the tool moves, material is forced to flow around the tool in a complex pattern. In the FSW process, parameter selection and tool geometry are among the key factors that determine the quality of the fabricated joint. Adjusting the values of different parameters, such as welding speed, rotational speed, tilt angle, and pin geometry, could lower the forces exerted from the TMAZ section to the tool. Consequently, the quality of the weld improves while less thermal energy is needed for the process of prompting both sheets to reach the plastic state. The plastic flow is responsible for obtaining a weld with high tensile strength and fewer defects and therefore the tool geometry plays an important role in achieving a high-quality weld. Geometrical parameters such as the height and the shape of the pin, as well as the shoulder end details, 
have an influence on both the metal flow and the heat generation owing to frictional forces developed. Furthermore, the force superimposed on the rotating tool during the process has to be controlled properly, since the pressure generated on the tool shoulder end determines the amount of heat generated during the process. It is found that friction-stir-welded butt joints are generally defect free if welding process conditions (welding speed and sheet thickness) are properly tuned within a 'tolerance box' for a particular alloy. It is not possible to assume that FSW will be free of flaws, however, because manufacturers may want to run FSW outside the tolerance box in order to increase productivity ( $P$ Bahemmat et al). Several researches have addressed the relation between adjustable parameters, fatigue characteristics, and mechanical and metallurgic properties of the weld in welding similar and dissimilar aluminium alloys. Their research revealed that the base material heat treatment was obviously related to weld morphologies, weld defects, and the tensile properties of the joints, as well as fracture location. They also investigated the effect of different tool pin geometries and rotational speeds on the weld quality of similar and dissimilar alloy joints. They used tensile properties, impact, flexural strength characteristics and macrostructure analysis to study the relation between FSW parameters and mechanical properties. They also studied the influence of welding speed on micro hardness distribution in the cross-section of a FSW weld. The relationship between the fracture direction during tensile testing and the hardness distribution was also investigated. However, researchers have not yet been drawn to study the hardness distribution, tensile test results, metallurgical properties, and the main causes of developing defects with changing FSW parameters for a dissimilar aluminium joint of AA6061-T651 and AA7075-T651. Selection of process parameters is an important issue in the FSW process, particularly in the case of joining dissimilar aluminium alloys. In the present investigation, the effect of different welding and the rotational speeds on the weld characteristics of AA7075-T651 and AA6061-T651 fabricated by a threaded taper tool and square tool pin profile is investigated. Impact and Bending characteristics for different welding and rotational speeds were measured. The properties of fabricated welds revealed that a proper selection of FSW parameters could result in an acceptable weld in dissimilar joints of aluminium alloys. Cavaliere et al [3] referred the 2024 and 7075 dissimilar joints exhibit very good ductile properties after yielding and the Ultimate Tensile Stress is settled at high levels. Even that the FS Welded specimens show lower proof stress at $0.2 \%$ and limited total elongations with respect to the base metals, the mechanical results are extremely good considering the drastic conditions to which the materials are subjected during the Friction Stirring process. The mechanical properties, compared to the parent metals, are reported in all the tested specimens fractured beside the weld HAZ zones, close to the 2024 material side. This is in accordance with the behaviour of dissimilar welded sheets in which, from a microstructural point of view, the mechanical response of the centre weld results higher than the parent material and the HAZ because of the grain dimension differences and the precipitates concentration at the interfaces. K. Elangovan et al [4] referred out of the three welded joints, the joints fabricated by FSW process exhibited higher strength values and the enhancement in strength value is approximately $34 \%$ compared to GMAW joints, and $15 \%$ compared to GTAW joints. Hardness is lower in the weld metal (WM) region compared to the $\mathrm{HAZ}$ and $\mathrm{BM}$ regions irrespective of welding technique. Very low hardness is recorded in the GMAW joints (58 VHN) and the maximum hardness is recorded in the FSW joints $(85$ VHN). The formation of fine, equiaxed grains and uniformly distributed, very fine strengthening precipitates in the weld region are the reasons for superior tensile properties of FSW joints compared to GTAW and GMAW joints. Fig. 6 shows the fracture locations of tensile specimen for GMAW, GTAW and FSW joints. $P$ Bahemmat et al [5] investigates the mechanical, micro- and macrostructural characteristics of the friction-stirwelded dissimilar joints of AA6061-T6 and AA7075-T6 alloys. This research reveals that there are severe defects in the joint fabricated at a welding speed of $160 \mathrm{~mm} / \mathrm{min}$. In addition, some small defects are found at higher magnification in the joints made at a speed of $120 \mathrm{~mm} / \mathrm{min}$. However, because of the higher strength of the SZ compared with the HAZ and the TMAZ, this specimen was not fractured in the SZ and the fracture occurred in the TMAZ-HAZ interface on the AA6061 side, which has lower hardness and strength in the weld cross-section. Furthermore, the tensile test shows that this specimen has superior ultimate stress owing to the higher hardness and strength of the HAZ (in which the fracture occurred) 
compared with those of the defect-free welds. So, in the dissimilar joint, if some defects are found in the SZ, there is no evidence to conclude that it should be ignored.

\section{EXPERIMENTAL PROCEDURE}

Aluminium alloys of AA6061-T651 and AA7075-T651 were selected for fabricating dissimilar joints using the FSW process. The thicknesses of both plates were $6.35 \mathrm{~mm}$. The plates were in a butt joint configuration and the welding process was carried out normal to the rolling direction of the plates. The dimensions of the aluminium plates are $200 \mathrm{~mm}$ length and $80 \mathrm{~mm}$ width. The chemical compositions of AA6061 T-651 and AA7075 T651 are given in Tables 1 \& Table 2 shows the mechanical properties of the base metals.

The welding process was accomplished at two rotational speeds, $800 \mathrm{rpm}$ and $900 \mathrm{rpm}$ keeping axial load $8 \mathrm{kN}$ and welding speed $250 \mathrm{~mm} / \mathrm{min}$ as constant in order to evaluate the effect of rotational speed on tensile, hardness, impact and bending properties for the joints. With two welding speeds, $150 \mathrm{~mm} / \mathrm{min}$ and 200 $\mathrm{mm} / \mathrm{min}$ keeping axial load $8 \mathrm{kN}$ and rotational speed $900 \mathrm{rpm}$ as constant to evaluate the effect of welding speed on tensile, hardness, impact and bending properties for the joints. For both set of experiments the tilt angle is set to zero and AA 7075-T651 placed in Advancing side whereas AA6061-T651 in retreating side. Two pin profiles taper cylindrical treaded and square geometry is used for experiments. The selected range of process parameter for dissimilar welding is shown in Table 3. The combination of process parameters for welding with various rotational and welding speeds are shown in Table $4 \& 5$ respectively. Fig 3 shows the two tools used for the experimental investigation. Fig 4 shows the friction stir welding machine in which the experiments are conducted.

Table 1. Chemical composition (wt \%) of AA 6061-T651 and AA7075-T651 Aluminium alloys

\begin{tabular}{|c|c|c|c|c|c|c|c|c|c|}
\hline \multicolumn{1}{|c|}{ Elements } & $\mathbf{S i}$ & $\mathbf{F e}$ & $\mathbf{C u}$ & $\mathbf{M n}$ & $\mathbf{M g}$ & $\mathbf{C r}$ & $\mathbf{Z n}$ & $\mathbf{T i}$ & $\mathbf{A l}$ \\
\hline AA 6061-T651 & 0.80 & 0.32 & 0.20 & 0.08 & 0.95 & 0.06 & 0.04 & 0.05 & Remainder \\
\hline AA7075-T651 & 0.06 & 0.13 & 1.30 & 0.03 & 2.39 & 0.20 & 5.85 & 0.07 & Remainder \\
\hline
\end{tabular}

Table 2. Mechanical properties of base metals

\begin{tabular}{|c|c|c|c|c|}
\hline Material & Yield stress (MPa) & Ultimate stress (MPa) & \% Elongation & Hardness (Rockwell) \\
\hline AA6061-T651 & 302.16 & 320.07 & 13.40 & 106.3 \\
\hline AA7075-T651 & 545.81 & 588.66 & 8.4 & 185.6 \\
\hline
\end{tabular}

Table 3. Selected range of FSW process parameters

\begin{tabular}{|c|l|}
\hline Welding speed in $\mathrm{mm} / \mathrm{min}$ & $150,200,250$ \\
\hline Rotational speed in $\mathrm{rpm}$ & 800,900 \\
\hline Axial load in $\mathbf{~ k N}$ & 8 \\
\hline Tool tilt angle in degrees & 0 \\
\hline
\end{tabular}

Table 4. Parameters of welded specimens for various rotational speeds

\begin{tabular}{|c|c|c|c|c|l|}
\hline $\begin{array}{c}\text { Parameter } \\
\text { Combinations }\end{array}$ & $\begin{array}{c}\text { Rotational } \\
\text { Speed (rpm) }\end{array}$ & $\begin{array}{c}\text { Welding Speed } \\
(\mathbf{m m} / \mathbf{m i n})\end{array}$ & $\begin{array}{c}\text { Tool tilt angle } \\
\mathbf{( d e g )}\end{array}$ & Axial Load (kN) & \multicolumn{1}{|c|}{ Tool pin profile } \\
\hline RS11 & 800 & 250 & 0 & 8 & Tap. Cylind threaded \\
\hline RS12 & 900 & 250 & 0 & 8 & Tap. Cylind threaded \\
\hline RS21 & 800 & 250 & 0 & 8 & Square \\
\hline RS22 & 900 & 250 & 0 & 8 & Square \\
\hline
\end{tabular}


Table 5. Parameter of welded specimens for various welding speeds

\begin{tabular}{|c|c|c|c|c|l|}
\hline $\begin{array}{c}\text { Parameter } \\
\text { Combinations }\end{array}$ & $\begin{array}{c}\text { Welding Speed } \\
(\mathbf{m m} / \mathbf{m i n})\end{array}$ & $\begin{array}{c}\text { Rotational } \\
\text { Speed (rpm) }\end{array}$ & $\begin{array}{c}\text { Tool tilt angle } \\
(\mathbf{d e g})\end{array}$ & Axial Load (kN) & Tool pin profile \\
\hline WS11 & 200 & 900 & 0 & 8 & Tap. Cylind threaded \\
\hline WS13 & 150 & 900 & 0 & 8 & Tap. Cylind threaded \\
\hline WS21 & 200 & 900 & 0 & 8 & Square \\
\hline WS23 & 150 & 900 & 0 & 8 & Square \\
\hline
\end{tabular}

Table 6. Pin profile geometry for taper threaded tool

\begin{tabular}{|l|l|}
\hline Pin dia (d) & $6.35 \mathrm{~mm}$ \\
\hline Pin length (L) & $6 \mathrm{~mm}$ \\
\hline Shoulder dia (D) & $19.05 \mathrm{~mm}$ \\
\hline D/d Ratio of tool & 3 \\
\hline Tilt angle & 0 \\
\hline Shoulder deepness & $0.2 \mathrm{~mm}$ \\
\hline Included angle of taper pin & 7.5 \\
\hline Pitch & $1 \mathrm{~mm}$ \\
\hline Thread angle & 60 \\
\hline Hardness of the tool & $50 \mathrm{Rc}$ \\
\hline Tool material & $\mathrm{M} 2 \mathrm{HSS}$ \\
\hline
\end{tabular}

Table 7. Pin profile geometry for square tool

\begin{tabular}{|l|l|}
\hline Pin side length & $6.35 \mathrm{~mm}$ \\
\hline Pin length (L) & $6 \mathrm{~mm}$ \\
\hline Shoulder dia (D) & $19.05 \mathrm{~mm}$ \\
\hline D/d Ratio of tool & 3 \\
\hline Tilt angle & 0 \\
\hline Shoulder deepness & $0.2 \mathrm{~mm}$ \\
\hline Hardness of the tool & $50 \mathrm{Rc}$ \\
\hline Tool material & M2 HSS \\
\hline
\end{tabular}

\section{RESULTS AND DISCUSSION}

\section{A. Experimental discussion}

In the FSW process, three factors contribute to the formation of the joints. The first phenomenon is the temperature increase in the welding region, which softens the BMs in the SZ. The second factor is the stirring of plastic materials, the process of accumulating multi-layer plasticized materials behind the tool, affected by the interaction of rotational and welding speeds and the pin profile. The last element is the hot forging of plasticized materials conducted by the shoulder. Any

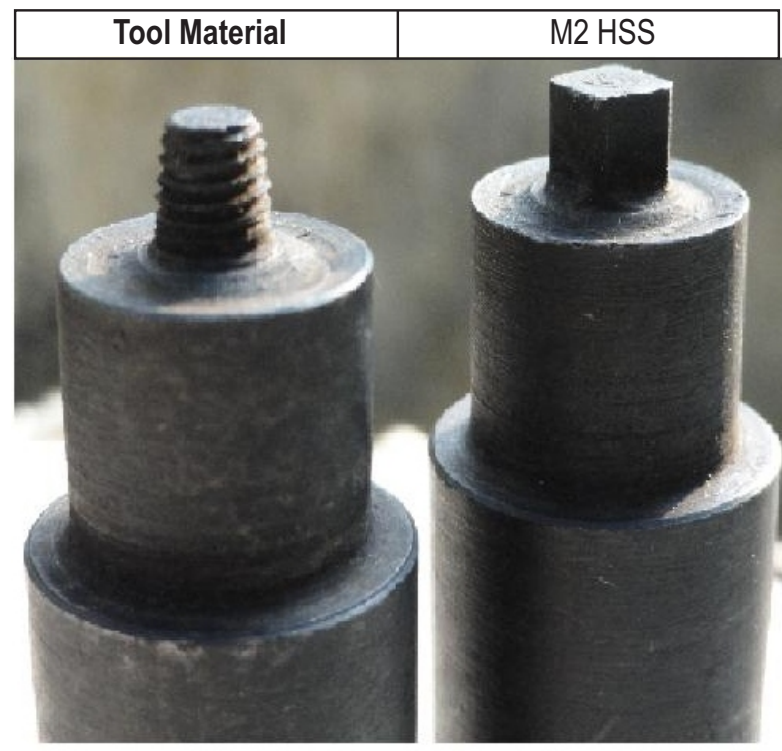

Fig. 3 Taper cylindrical threaded and square tool used for investigation

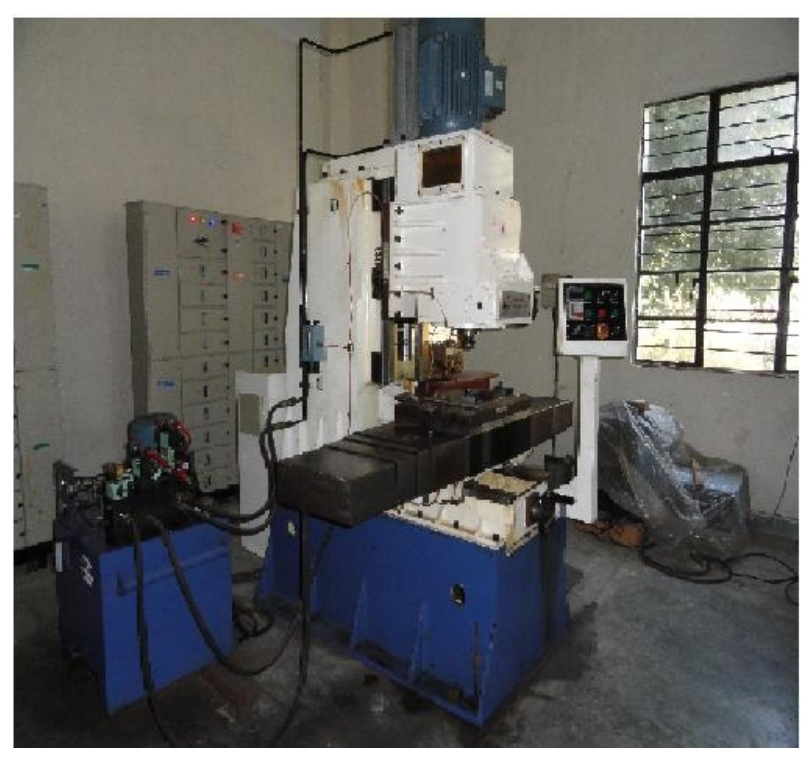

Fig. 4 Set up of the FSW equipment 
inappropriate adjustment of these factors results in defective joints.

The following factors should be considered for controlling the temperature of the welding zone: ( $P$ Bahemmat et al).

(a) The ratio of shoulder diameter to pin diameter;

(b) The heat sinking owing to the forward movement of the tool;

(c) The heat generated as a result of the rotational movement of the tool.

In this experiment, the ratio of the shoulder diameter to the pin diameter was assumed to be constant and, therefore, the only parameter affecting the temperature rise in the welding zone was the welding speed and Rotational speed. Since the temperature increase at the welding speed of 250 $\mathrm{mm} / \mathrm{min}$ was not enough to soften the base material, the materials were not sufficiently plasticized to be stirred and forged easily. Defect in the root of the specimen fabricated at a welding speed of 250 $\mathrm{mm} / \mathrm{min}$. This defect, known as the 'Tunnel hole defect', has occurred. Though the appearance of the welded surface seems to be good, tunnel defects could be observed at the advancing side of the weld. The plastized metal under the shoulder cannot flow sufficiently during the welding process due to insufficient heat generation. This problem can be alleviated by optimizing the process parameters, particularly by reducing the welding speed and increasing the rotational speed and the depth of the pin penetration in the BMs. At the welding speed of $150 \mathrm{~mm} / \mathrm{min}$, the temperature did not increase enough, so the BMs did not adequately soften. In the FSW process, the thermomechanical cycle experienced by the material in the SZ of aluminium alloys essentially involves hot working. The SZ is subjected to the greatest strain and strain rates as well as the highest temperatures. A combination of these parameters apparently results in dissolution of strengthening precipitates as well as continuous dynamic recrystallization (CDRX). So the large grains in the BM were dynamically recrystallized in the SZ owing to the higher plastic deformations, high temperatures and precipitate dissolution; therefore, the grains coarsen in the SZ. A noticeable point is that AA6061 and AA7075 alloys are classified into heat-treatable (precipitation-hardenable) alloys and the hardness profile in these alloys is strongly affected by the precipitate distributions rather than the grain size $(P$ Bahemmat et al). So precipitate dissolution and coarsening make the hardness of the SZ become less than the hardness of the BMs. Although the TMAZ undergoes plastic deformation, recrystallization usually does not occur in this zone owing to insufficient deformation strain. HAZ experiences a thermal cycle but does not undergo any plastic deformation the predicted peak temperature is between 90 to 150 deg C.

\section{B. Effect of rotational speed on tensile strength}

Since the percentage of elongation values are very less for the entire Tensile tested specimen so the values in $\mathrm{MPa}$ are comparatively less for all the range of rotational parameters. Since the predicted temperature range also less the base alloys are not soften with stirring. The materials are not thoroughly mixed during the welding process. If we go for lower welding speeds in the range $90-120 \mathrm{~mm} / \mathrm{min}$ and the rotational speed above 800-900 rpm. We can get the high Tensile strength for both the pin profiles combinations. All the tensile specimens are fracture in the welded area. The specimens are mostly failing at the HAZ of the retreating side (AA 6061-T651) which have the lowest hardness values. Table - 8 represents the combinations and the values of both tensile strength and $\%$ of elongation for rotational speeds.

Table 8. Tensile strength for Rotational speed combinations

\begin{tabular}{|c|c|c|}
\hline $\begin{array}{c}\text { Parameter } \\
\text { Combinations }\end{array}$ & $\begin{array}{c}\text { Tensile } \\
\text { strength (MPa) }\end{array}$ & $\begin{array}{c}\text { Elongation on } \\
50 \mathrm{~mm} \text { G.L. } \\
(\%)\end{array}$ \\
\hline RS11 & 84.40 & 1.0 \\
\hline RS12 & 71.77 & 2.0 \\
\hline RS21 & 83.54 & 1.0 \\
\hline RS22 & 73.23 & 1.6 \\
\hline
\end{tabular}

C. Effect of welding speed on tensile strength

Since the percentage of elongation values are very less for the entire Tensile tested specimen so the values in MPa are comparatively less for all the range of welding speed parameters. Since the predicted temperature range also less the base alloys are not soften with stirring. The materials are not thoroughly mixed during the welding process. If we go for lower 
welding speeds in the range $90-120 \mathrm{~mm} / \mathrm{min}$ and the rotational speed above $800-900 \mathrm{rpm}$. We can get the high Tensile strength for both the pin profiles combinations. All the tensile specimens are fracture in the welded area. The specimens are mostly failing at the HAZ of the retreating side (AA 6061-T651) which have the lowest hardness values. Table 9 represents the combinations and the values of both tensile strength and $\%$ of elongation for welding speeds.

Table 9. Tensile strength for Welding speed combinations

\begin{tabular}{|c|c|c|}
\hline $\begin{array}{c}\text { Parameter } \\
\text { Combinations }\end{array}$ & $\begin{array}{c}\text { Tensile } \\
\text { strength (MPa) }\end{array}$ & $\begin{array}{c}\text { Elongation on } \\
\text { 50 } \mathbf{~ m m ~ G . L . ~ ( \% ) ~}\end{array}$ \\
\hline WS11 & 68.46 & 1.2 \\
\hline WS13 & 86.73 & 2 \\
\hline WS21 & 75.18 & 1.4 \\
\hline WS23 & 62.06 & 1 \\
\hline
\end{tabular}

D. Effect of rotational speed on hardness value

Table 10 represents the combinations and the hardness values of HAZ, TMAZ and SZ for the joints with rotational speeds. For all the combinations of rotational speeds the hardness value for AA6061- HAZ is very less where the failure takes place.

Table 10. Zonal hardness for Rotating speed combinations $(\mathrm{Hv}-0.5 \mathrm{Kg})$

\begin{tabular}{|c|c|c|c|c|c|}
\hline $\begin{array}{c}\text { Parameter } \\
\text { Combinations }\end{array}$ & $\begin{array}{c}\text { HAZ } \\
\mathbf{6 0 6 1}\end{array}$ & $\begin{array}{r}\text { TMAZ } \\
\mathbf{6 0 6 1}\end{array}$ & SZ & $\begin{array}{r}\text { TMAZ } \\
\mathbf{7 0 7 5}\end{array}$ & $\begin{array}{c}\text { HAZ } \\
\mathbf{7 0 7 5}\end{array}$ \\
\hline RS11 & 72.50 & 75.10 & 96.60 & 31.4 & 127.90 \\
\hline RS12 & 81.20 & 81.10 & 136.4 & 140.3 & 136.6 \\
\hline RS21 & 70.60 & 69.40 & 131.1 & 133.1 & 132.0 \\
\hline RS22 & 73.30 & 73.10 & 133.3 & 138.7 & 128.3 \\
\hline
\end{tabular}

E. Effect of welding speed on hardness value

Table 11. Zonal hardness for Welding speed combinations $(\mathrm{Hv}-0.5 \mathrm{Kg})$

\begin{tabular}{|c|c|c|c|c|c|}
\hline $\begin{array}{c}\text { Parameter } \\
\text { Combinations }\end{array}$ & $\begin{array}{c}\text { HAZ } \\
\mathbf{6 0 6 1}\end{array}$ & $\begin{array}{c}\text { TMAZ } \\
\mathbf{6 0 6 1}\end{array}$ & SZ & $\begin{array}{c}\text { TMAZ } \\
\mathbf{7 0 7 5}\end{array}$ & $\begin{array}{c}\text { HAZ } \\
\mathbf{7 0 7 5}\end{array}$ \\
\hline WS11 & 76.8 & 74.1 & 110.1 & 133.6 & 138.1 \\
\hline WS13 & 76.6 & 74.2 & 81.7 & 133.0 & 134.1 \\
\hline WS21 & 72.7 & 73.4 & 131.9 & 134.4 & 136.4 \\
\hline WS23 & 79.5 & 76.5 & 124.9 & 116.5 & 133.6 \\
\hline
\end{tabular}

Table 11 represents the combinations and the hardness values of HAZ, TMAZ and SZ for the joints with welding speeds. For all the combinations of welding speeds the hardness value for AA6061- HAZ is very less where the failure takes place.

\section{F. Effect of rotational and welding speed on impact strength}

Since the percentage of elongation values are very less for the entire tested specimen so the values in $\mathrm{MPa}$ are comparatively less for all the range of rotational parameters. Since the temperature range also less the base alloys are not soften with stirring. The materials are not thoroughly mixed during the welding process. If we go for lower welding speeds in the range $90-120 \mathrm{~mm} / \mathrm{min}$ and the rotational speed above $800-900 \mathrm{rpm}$. We can get the high impact and bending strength for both the pin profiles combinations. All the specimens are fracture in the welded area. The specimens are mostly failing at the HAZ of the retreating side (AA 6061-T651) which have the lowest hardness values. Table 12 \& 13 represents the combinations and the values of impact strength and \% of elongation for rotational and welding speeds.

Table 12. Impact strength for Rotational speed combinations

\begin{tabular}{|c|c|c|}
\hline $\begin{array}{c}\text { Parameter } \\
\text { Combinations }\end{array}$ & $\begin{array}{c}\text { Charpy impact } \\
\text { test, (Joules) }\end{array}$ & $\begin{array}{c}\text { Elongation on } \\
\mathbf{5 0} \text { mm G.L. (\%) }\end{array}$ \\
\hline $\mathrm{RS} 11$ & 2 & 1 \\
\hline $\mathrm{RS} 12$ & 2.67 & 2 \\
\hline $\mathrm{RS} 21$ & 2 & 1 \\
\hline $\mathrm{RS} 22$ & 2 & 1.6 \\
\hline
\end{tabular}

Table 13. Impact strength for Welding speed combinations

\begin{tabular}{|c|c|c|}
\hline $\begin{array}{c}\text { Parameter } \\
\text { Combinations }\end{array}$ & $\begin{array}{c}\text { Charpy impact } \\
\text { test, (Joules) }\end{array}$ & $\begin{array}{c}\text { Elongation on } \\
\text { 50 } \mathbf{~ m m ~ G . L . ~ ( \% ) ~}\end{array}$ \\
\hline WS11 & 2.67 & 1.2 \\
\hline WS13 & 3.3 & 2 \\
\hline WS21 & 2 & 1.4 \\
\hline WS23 & 2.67 & 1 \\
\hline
\end{tabular}

Since the percentage of elongation values are very less for the entire impact tested specimen. So the values in joules are comparatively less for all the range of rotational and welding speed parameters. Since the 
temperature range also less the base alloys are not soften with stirring. The materials are not thoroughly mixed during the welding process. If we go for lower welding speeds in the range $90-120 \mathrm{~mm} / \mathrm{min}$ and the rotational speed above $800-900 \mathrm{rpm}$.

\section{G. Effect of rotational and welding speed on bending strength}

Table 14. Impact strength for Rotational speed combinations

\begin{tabular}{|c|c|c|c|}
\hline $\begin{array}{c}\text { Parameter } \\
\text { combinations }\end{array}$ & $\begin{array}{c}\text { Bend test, 4t } \\
\text { (180 deg), } \\
\text { for Root and } \\
\text { Face bend }\end{array}$ & $\begin{array}{c}\text { Elongation } \\
\text { on 50 } \\
\text { mm G.L. } \\
\text { (\%) }\end{array}$ & $\begin{array}{c}\text { Tensile } \\
\text { strength } \\
\text { (Mpa) }\end{array}$ \\
\hline RS11 & Crack at weld & 1 & 84.44 \\
\hline RS12 & Crack at weld & 2 & 71.77 \\
\hline RS21 & Crack at weld & 1 & 83.54 \\
\hline RS22 & Crack at weld & 1.6 & 73.23 \\
\hline
\end{tabular}

Table $14 \& 15$ represents the combinations and the values of bending strength and \% of elongation for rotational and welding speeds.

Table 15. Impact strength for Welding speed combinations

\begin{tabular}{|c|c|c|c|}
\hline $\begin{array}{c}\text { Parameter } \\
\text { Notation }\end{array}$ & $\begin{array}{c}\text { Bend test, 4t } \\
\text { (180 deg), for } \\
\text { Root and Face } \\
\text { bend }\end{array}$ & $\begin{array}{c}\text { Elongation } \\
\text { on 50 } \\
\text { mm G.L. } \\
\text { (\%) }\end{array}$ & $\begin{array}{c}\text { Tensile } \\
\text { strength } \\
\text { (Mpa) }\end{array}$ \\
\hline WS11 & Crack at weld & 1.2 & 68.46 \\
\hline WS13 & Crack at weld & 2 & 86.73 \\
\hline WS21 & Crack at weld & 1.4 & 75.18 \\
\hline WS23 & Crack at weld & 1 & 62.06 \\
\hline
\end{tabular}

Since the percentages of elongation and the tensile strength values are very less for the entire bending tested specimen, they are cracked at the welded area (stirred zone) where least strength is identified comparing to two base metals to all the range of rotational and welding speed parameters. Since the temperature range also less the base alloys are not soften with stirring. The materials are not thoroughly mixed during the welding process. If we go for lower welding speeds in the range $90-120 \mathrm{~mm} / \mathrm{min}$ and the rotational speed above $800-900 \mathrm{rpm}$ we can get the high bending strength for both the pin profiles combinations.

\section{CONCLUSION}

The percentages of elongation values are very less for the entire tested specimens, so the values in $\mathrm{MPa}$ are comparatively less for the tested range of rotational and welding speed parameters. The percentage of elongation and the tensile strength values are very less for the entire Tensile tested specimen and they are cracked at the welded area (stirred zone) where least strength is identified comparing to two base metals for the tested range of rotational and welding speed parameters. Since the temperature range is 90 to $150 \mathrm{deg}$ for which the base alloys are not soften with stirring. If we go for lower welding speeds in the range $90-120 \mathrm{~mm} / \mathrm{min}$ and the rotational speed between 800-900 rpm, we can get the high tensile, impact and bending strength and good hardness characteristic for both the pin profiles combinations. The Tunnel hole defect is identified for all the tested specimens in the AA7075 side (advancing side) and it is minimum for the rotational speed 900 rpm and welding speed $150 \mathrm{~mm} / \mathrm{min}$ where as is maximum to $800 \mathrm{rpm}$ and for both $200 \& 250 \mathrm{~mm} / \mathrm{min}$.

The suggested range of process parameters from the experiments to enhance the strength are

(a) Welding speed - 90 to $120 \mathrm{~mm} / \mathrm{min}$

(b) Rotational speed - 800 to $900 \mathrm{rpm}$

(c) Axial load - 15 to $20 \mathrm{kN}$

(d) Tool angle -1 to $2^{\circ}$

In the selected range and the combination of parameters from the experiment conducted both the pin profiles are giving almost same characteristics. If the welding speed reduced in the range of 90 to 120 $\mathrm{mm} / \mathrm{min}$, the temperature is sufficiently increased, for thorough mixing between the alloys to enhance strength.

Axial load should be increased from $8 \mathrm{kN}$ to 15-20 kN range, for good tool penetration and weld consolidation for to enhance the strength. Tool tilt angle should be in the range of 1 - 2 degree for a good ploughing action between two alloys to mix properly for to enhance the strength. If the experiment conducted in the above suggested range of process parameters, we can enhance the strength for dissimilar joints. 


\section{ACKNOWLEDGEMENT}

The author is grateful to SSN College of Engineering, Chennai for providing their FSW machine to carry out this investigation. Author is personally indebted to Mechanical department of SSN College of Engineering for having been a constant source of support and encouragement for the completion of experiments.

\section{REFERENCES}

[1] Terry Khalid, 2005 An outsider looks at friction stir welding, Report \#ANM-112N-05-06.

[2] Threadgill P.L., 2007 Terminology in friction stir welding, Science and Technology of Welding and Joining, Vol 12 No. 4 357-360.

[3] Cavaliere P., Nobilea R., Panella F.W., Squillace A., 2006 Mechanical and microstructural behaviour of 2024 -7075 aluminium alloy sheets joined by friction stir welding, International Journal of Machine Tools \& Manufacture 46 pp. 588-594.

[4] Lakshminarayanan A.K., Balasubramanian V., Elangovan K., 2007 Effect of welding processes on tensile properties of AA6061 aluminium alloy joints, Int J Adv Manuf Technology, pages - 11.

[5] Bahemmat P., Haghpanahi M., Besharati M.K., Ahsanizadeh S., and Rezaei H., 2010 Study on mechanical, micro, and macrostructural characteristics of dissimilar friction stir welding of AA6061-T6 and
AA7075-T6, Proc. IMechE Vol. 224 Part B: J. Engineering Manufacture, pages-1854-1864.

[6] Rhodes, C.G., Mahoney, M.W., and Bingel, W.H., 1997 Effects of friction stir welding on microstructure of 7075 aluminum. Scripta Mater., 36, 69-75.

[7] Elangovan, K. and Balasubramanian, V., 2007, Influences of pin profile and rotational speed of the tool on the formation of friction stir processing zone in AA2219 aluminum alloy. Mater. Sci. Engng A, 459, 7-18.

[8] Bahemmat, P., Besharati, M.K., Haghpanahia, M., Rahbari, A., and Salekrostam, R. 2010, Mechanical, micro and macrostructural analysis of AA7075 - T fabricated by friction stir butt welding with different rotational speeds and tool pin profiles. Proc. IMechE, Part B: J. Engineering Manufacture, 224 (B3), 419-433. DOI: 10.1243/09544054JEM1554.

[9] Cavaliere, P., De, Santis A., Panella, F., and Squillace, A., 2008, Effect of welding parameters on mechanical and microstructural properties of dissimilar AA6082AA2024 joints produced by friction stir welding. Mater. Des., 30, 609-616.

[10] Moreira, P., Santos, T., Tavares S., Richter, V., Vilaça, P., and De Castro, P., 2009, Mechanical and metallurgical characterization of friction stir welding joints of AA6061-T6 with AA6082-T6. Mater. Des., 30, 180-187.

[11] Mishra, R.S. and Ma, Z.Y., 2005, Friction stir welding and processing, Mater. Sci. Engng R, 50, 1-78. 